\title{
Subclinical Hypothyroidism Is Characterized by Increased QT Interval Dispersion among Women
}

\author{
O. Bakiner M.E. Ertorer F.E. Haydardedeoglu E. Bozkirli N.B. Tutuncu \\ N.G. Demirag \\ Faculty of Medicine, Division of Endocrinology and Metabolism, Baskent University, Adana, Turkey
}

\section{Key Words}

Hypothyroidism · Thyroid hormones $\cdot$ Sudden death • Thyroxine

\begin{abstract}
Objective: Increased QT interval dispersion (QTd) is an electrocardiographic parameter shown to be associated with malignant ventricular arrhythmias and sudden death, and QT dispersion corrected for heart rate (QTC) has emerged as a potentially important predictor of cardiac death. Increased QTd has been detected to be directly related to thyroid-stimulating hormone (TSH) levels in overt hypothyroidism, however not much is known about subclinical hypothyroidism (SH). This study was conducted to investigate the QTc in SH and determine the changes following normalization of TSH levels with L-thyroxine. Subjects and Methods: Fifty-eight women with naive SH due to Hashimoto's thyroiditis, mean age $39.37 \pm 10.43$ years, and 54 age-, sex- and weightmatched controls with normal TSH were included after exclusion of any factor that might interfere with cardiac conductibility. Electrocardiographic measurements were performed with a magnifier and Bazett's formula was used to calculate QTc. The patients were separated into two groups regarding basal TSH levels (subgroup A: $5>\mathrm{TSH}>10 \mathrm{mIU} / \mathrm{l}$, $\mathrm{n}=36$; subgroup $\mathrm{B}$ : $\mathrm{TSH}>10 \mathrm{mIU} / \mathrm{l}, \mathrm{n}=22$ ). L-Thyroxine $1-2$ $\mu \mathrm{g} / \mathrm{kg} /$ day was administered to subgroup B. Results: Mean
\end{abstract}

QTc interval of the study group was significantly longer than that of the control group $(100 \pm 30$ vs. $76 \pm 30 \mathrm{~ms}, \mathrm{p}=$ 0.000). It was also longer in subgroup $A(5>\mathrm{TSH}>10 \mathrm{mIU} / \mathrm{l}$, $n=36)$ and subgroup $B(p=0.001, p=0.000$, respectively). In subgroup $B$, following normalization of serum TSH, mean post-treatment QTc measurement was similar to that of the control group ( $75 \pm 40$ vs. $76 \pm 30 \mathrm{~ms}, \mathrm{p}>0.05)$. Conclusion: We detected prolonged QTc among SH cases. Prolongation remained significant for the whole group as well as the two subgroups. The differences in QTc were corrected when TSH levels of $>10 \mathrm{mlU} / \mathrm{l}$ returned to normal.

Copyright $\odot 2008$ S. Karger AG, Basel

\section{Introduction}

Subclinical hypothyroidism ( $\mathrm{SH}$ ) is a common disorder characterized by elevated serum thyroid-stimulating hormone (TSH), normal free thyroxine $\left(\mathrm{fT}_{4}\right)$ and free triiodothyronine $\left(\mathrm{fT}_{3}\right)$ levels. Its prevalence reportedly ranges between 1.3 and $17.5 \%$, depending on age, gender and the amount of iodine exposure [1-3]. Despite its adverse cardiovascular risk profile, the exact TSH level at which the treatment of SH should be started remains undetermined [4-7].

QT interval dispersion (QTd) is an index of the inhomogeneity of ventricular repolarization and is used in as-

\section{KARGER}

Fax +41613061234 E-Mail karger@karger.ch www.karger.com (c) 2008 S. Karger AG, Basel

$1011-7571 / 08 / 0175-0390 \$ 24.50 / 0$

Accessible online at:

www.karger.com/mpp
Okan Bakiner, MD

Division of Endocrinology and Metabolism, Baskent University Faculty of Medicine Adana Medical Center, Dadaloglu mah. Serin Evler 39. sok. no. 6

TR-01250 Yuregir/Adana (Turkey)

Tel. +90 322327 2727-2197, Fax +90 322327 1274, E-Mail okanbakiner@mynet.com 
sessment of cardiovascular risk [8]. Increased QTd has been shown to be associated with malignant ventricular arrhythmias and sudden death [9-11]. QT dispersion corrected for heart rate $(\mathrm{QTc})$ has emerged as a potentially important predictor of cardiac death [12-14].

Overt hypothyroidism is associated with many cardiac manifestations, such as prolongation of QRS and QT intervals $[15,16]$. QT prolongation and increased QTd have been shown to be directly related to TSH level in overt hypothyroidism [17]. However, not much is known about the changes that may occur in $\mathrm{SH}$. A review of the literature reveals only one study regarding the presence of such alterations in $\mathrm{SH}$ performed on a limited number of cases who are relatively older [18].

In this study, we aimed to investigate the changes in QT intervals and QTc among women with SH and determine the alterations following normalization of TSH levels in a subgroup with TSH $>10 \mathrm{mIU} / \mathrm{l}$.

\section{Subjects and Methods}

\section{Subjects}

Fifty-eight women with naive SH due to Hashimoto's thyroiditis participated in this study. Inclusion of the cases was performed in a two-step approach. The first was the selection of cases with high serum autoantibody levels (antithyroglobulin and antithyroperoxidase) and elevated TSH (above the upper limit, $4.94 \mathrm{mIU} / \mathrm{l}$, of the laboratory reference range: $0.30-4.94 \mathrm{mIU} / \mathrm{l}$ ), with normal $\mathrm{fT}_{3}$ and $\mathrm{fT}_{4}$. As a second step, cases were subjected to detailed investigation to rule out underlying cardiac pathology.

Criteria for exclusion were as follows: accompanying cardiovascular disease, arrhythmia, hypertension, diabetes, hepatic or renal failure (either current or reported to have occurred in the past); consumption of any medication that might interfere with cardiac conductibility; current serum electrolyte abnormalities, including hypocalcemia or hypercalcemia; detection of blood pressure above $140 / 90 \mathrm{~mm} \mathrm{Hg}$ and pulse rate beyond the range of 60-100 beats per minute; detection of QRS complex longer than $0.12 \mathrm{~s}$, T-wave flattening or negativity or biphasic $\mathrm{T}$ waves at a minimum of three derivations during the performance of 12 channel electrocardiographic evaluation (with a rate of $25 \mathrm{~mm} / \mathrm{s}$ ) during morning hours (8.00-10.00 a.m.).

To meet the second criterion, all cases enrolled in accordance with the criteria mentioned above were subjected to detailed cardiovascular investigation, including performance of myocardial perfusion scintigraphy with ${ }^{99 \mathrm{~m}} \mathrm{Tc}$, and detection of the structure and output of the heart by echocardiography. None of the subjects were excluded due to a cardiac problem. The study group was separated into subgroups according to the TSH values: those with TSH between 5 and $10 \mathrm{mIU} / \mathrm{l}$ (subgroup A, $\mathrm{n}=36$ ) and those with TSH over $10 \mathrm{mIU} / \mathrm{l}$ (subgroup B, $\mathrm{n}=22$ ).

Age- and weight-matched healthy women $(n=54)$ with normal thyroid function and negative thyroidal antibodies were included as a control group. The previously listed exclusion criteria were also applied to them.

QTc in Subclinical Hypothyroidism
The Baskent University Ethics Committee for Human Studies approved of the protocol. All patients provided written informed consent.

\section{Measurements}

All cases underwent anthropometric investigation. Body weight was measured in light clothing without shoes, and body mass index (BMI) was calculated by dividing the weight in kilograms by height in meters squared. Blood pressure was measured with a standard mercury manometer after a 15 -min rest in a sitting position. Pulse rate obtained from the radial artery was also recorded.

Venous blood samples were taken in the morning following $12 \mathrm{~h}$ of overnight fasting. Serum $\mathrm{Na}$ and $\mathrm{K}$ levels were determined by ion-selective electrode method, and Mg levels were measured by a photometric method using the xylidyl blue method (Roche Diagnostics $\mathrm{GmbH}$, Mannheim, Germany). Samples were assayed for ionized $\mathrm{Ca}$, using a Gem Premier 3000 blood-gas analyzer (Instrumentation Laboratory SpA, Milan, Italy). Serum $\mathrm{TSH}, \mathrm{fT}_{3}$ and $\mathrm{fT}_{4}$ levels were measured by chemoluminescence microparticle immunoassay method using Abbott-Architect analyzer (Abbott Laboratories, Abbott Park, Ill., USA).

Electrocardiograms of the participants were examined manually with a magnifier. The QT intervals were measured at a minimum of 9 derivations (at least 3 of them belonged to the chest). All measurements were performed by the same researcher and owing to the well-known difficulties with the definition of the end of $\mathrm{T}$ wave, they were reanalyzed by 2 independent observers [19]. All were blinded to the group assignation.

Measurements were performed from the point where the $\mathrm{Q}$ wave started and the $\mathrm{T}$ wave returned to the isoelectric line. Heart rate was corrected by using the Bazett formula; the longest QT (QTmax) and the shortest QT (QTmin) intervals were determined, the distance between the peak points of two R waves was measured, then correction was performed applying the values to the formula $\mathrm{QTc}=\mathrm{QT} / \sqrt{\mathrm{RR}}$, and QTcmax and QTcmin were calculated. The difference was recorded as corrected QT dispersion (QTc) [20].

Thereafter, L-thyroxine $1-2 \mu \mathrm{g} / \mathrm{kg} /$ day was administered to the cases whose serum TSH levels were above $10 \mathrm{mIU} / \mathrm{l}$ (subgroup $\mathrm{B}, \mathrm{n}=22$ ). Following normalization of TSH levels for at least 3 months, the procedures mentioned above were reperformed in this subgroup.

\section{Statistics}

SPSS software (Statistical Package for the Social Sciences, version 11.0, SSPS Inc., Chicago, Ill., USA) was used for the statistical analyses. Data are presented as means \pm SD. A value of $\mathrm{p}<0.05$ was considered statistically significant. Descriptive analysis, onesample t test, independent samples t test, and Pearson's correlation test were used where appropriate.

\section{Results}

A total of 112 subjects, 58 in the study group and 54 in the control group, were included. The clinical and biochemical characteristics of the groups are shown in table 1 . 
Table 1. Clinical and biochemical characteristics of the groups $($ mean $\pm \mathrm{SD})$

\begin{tabular}{lcc}
\hline & $\mathrm{SH}(\mathrm{n}=58)$ & Controls $(\mathrm{n}=54)$ \\
\hline Age, years & $39.37 \pm 10.43$ & $40.72 \pm 9.65$ \\
$\mathrm{BMI}, \mathrm{kg} / \mathrm{m}^{2}$ & $27.08 \pm 2.12$ & $26.92 \pm 2.64$ \\
$\mathrm{HR}, \mathrm{bpm}$ & $73.56 \pm 5.46$ & $74.56 \pm 5.13$ \\
$\mathrm{SBP}, \mathrm{mm} \mathrm{Hg}$ & $11.52 \pm 11.79$ & $110.39 \pm 11.12$ \\
$\mathrm{DBP}, \mathrm{mm} \mathrm{Hg}$ & $72.61 \pm 6.51$ & $74.04 \pm 6.8$ \\
$\mathrm{TSH}, \mathrm{mIU} / \mathrm{l}(0.30-4.94)^{*}$ & $9.28 \pm 3.24$ & $1.38 \pm 0.79$ \\
$\mathrm{fT}_{4}, \mathrm{pmol} / \mathrm{l}(9-25)$ & $11.85 \pm 2.10$ & $12.50 \pm 2.51$ \\
Glucose, $\mathrm{mmol} / \mathrm{l}$ & $4.49 \pm 0.43$ & $4.62 \pm 0.48$ \\
Calcium, mmol/l & $2.37 \pm 0.09$ & $2.33 \pm 0.12$ \\
\hline
\end{tabular}

$\mathrm{HR}=$ Heart rate; $\mathrm{SBP}=$ systolic blood pressure $\mathrm{DBP}=$ dia stolic blood pressure. Laboratory reference ranges are given in parentheses.

${ }^{*} \mathrm{p}<0.0001$ vs. controls.

Table 2. QTc interval and QTc dispersion measurements (ms) in control and $\mathrm{SH}$ patient groups (mean $\pm \mathrm{SD}$ )

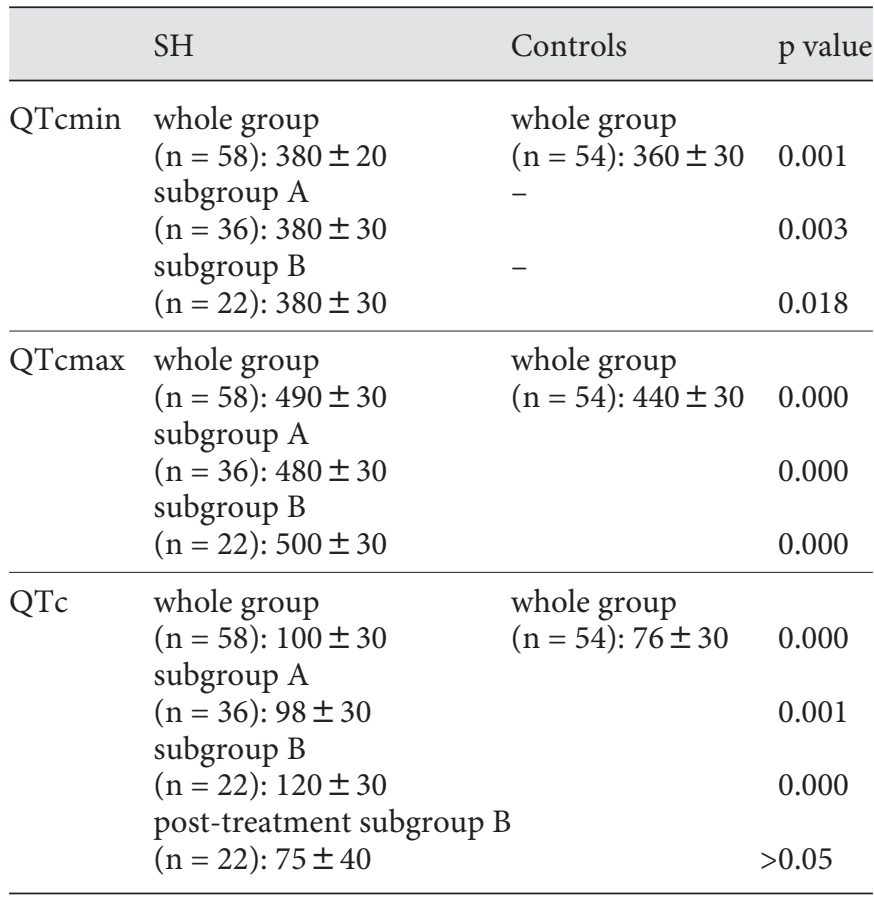

Serum TSH levels: 5-10 mIU/l (subgroup A), >10 mIU/l (subgroup B).

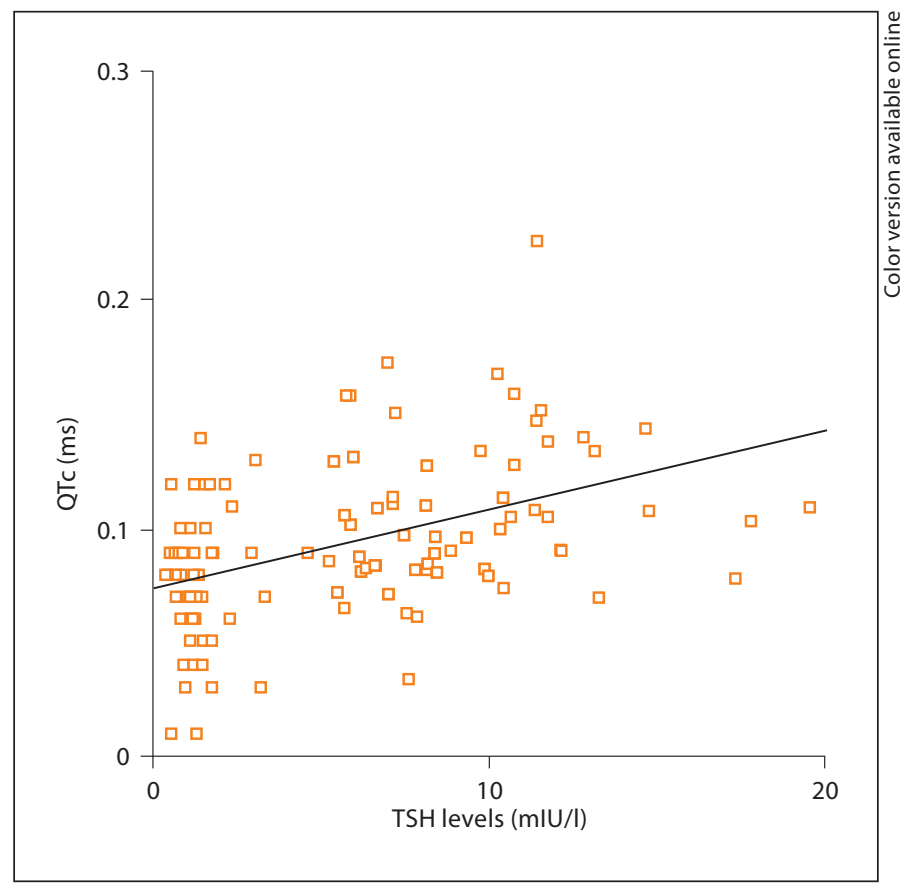

Fig. 1. Correlation between serum TSH levels and QTc for all patients and control subjects $(\mathrm{n}=112, \mathrm{r}=0.44, \mathrm{p}=0.000)$.

Both subgroups A and B exhibited similar age and BMI when compared to the control group; subgroup A: $40.06 \pm 9.49$ years $(22-56)$ and $27.79 \pm 1.76 \mathrm{~kg} / \mathrm{m}^{2}$; subgroup B: $41.82 \pm 10.05$ years $(21-55)$ and $28.01 \pm 1.89$ $\mathrm{kg} / \mathrm{m}^{2}$, respectively $(\mathrm{p}>0.05)$.

Mean QTcmin and QTcmax intervals (table 2) of the study group were significantly longer than those of the control group ( $\mathrm{p}=0.001, \mathrm{p}=0.000$, respectively). The differences between the control group and subgroups $A$ and B were also significant, $\mathrm{p}$ values being 0.003 and 0.018 , respectively, for QTcmin, 0.000 and 0.000 for QTcmax.

In the whole patient group, the mean QTc interval was also significantly longer than that of the control group $(p=0.000)$. Such a difference was also found between control subgroups A and $B(p=0.001, p=0.000$, respectively).

There was a positive correlation between TSH levels and QTc intervals of 112 subjects $(\mathrm{r}=0.44, \mathrm{p}=0.000)$ (fig. 1). The average QTc interval for subgroup B was longer than that for subgroup A, being $120 \pm 30$ vs. $98 \pm 30$ $\mathrm{ms}$, respectively $(\mathrm{p}=0.009)$.

The cases in subgroup B $(n=22)$ received L-thyroxine treatment. The final mean L-thyroxine dose was $1.18 \pm 0.34 \mu \mathrm{g} / \mathrm{kg} / \mathrm{day}$ and mean TSH level was 2.68 
$\pm 1.34 \mathrm{mIU} / \mathrm{l}$. They exhibited similar final BMI values as the control group $\left(27.82 \pm 2.34\right.$ vs. $26.92 \pm 2.64 \mathrm{~kg} / \mathrm{m}^{2}$, $\mathrm{p}>0.05)$. Their mean post-treatment QTc was also similar to that of the control group $(75 \pm 40$ vs. $76 \pm 30 \mathrm{~ms}$, $\mathrm{p}>0.05)$.

\section{Discussion}

Prolonged QT intervals reflect prolonged ventricular repolarization among patients with overt hypothyroidism [21]. A review of the literature revealed that an increase ranging between 31 and $44 \%$ was reported in the ventricular action potential of hypothyroid guinea pigs, and this effect was attributed to the $41 \%$ decrease in the amplitude of L-type Ca current (ICa) in the myocyte membrane $[22,23]$. Ventricular membrane repolarization was also shown to be delayed in these animals and the decrease in the slow component of delayed rectifier $\mathrm{K}$ current (IKs) was claimed to be primarily responsible for this situation [24].

In a very recent trial, and for the first time in the literature, it has been demonstrated that $\mathrm{SH}$ can alter autonomic modulation of heart rate and cause increased inhomogeneity of ventricular recovery times [18]. Our results were compatible with that study. In younger SH patients, we also detected significant prolongation in QT intervals and an increase in QTc, which correlated positively with TSH. The QT intervals and QTc significantly normalized following L-thyroxine replacement therapy, as well. Our results clearly demonstrated the favorable effects of achieving euthyroidism on the electrophysiology of the heart.

When compared with ours, the study mentioned above had some limitations [18]. It was performed with a lower number of cases ( $n=42$ in the study group and $n=30$ in controls) and since the mean age of the participants was about 50 years, they were significantly older than our cases. Although it was well known that gender might have an influence on QTd, both males and females were included. More detailed cardiac evaluation using scintigraphy and echocardiography was carried out in our study, whereas basal and stress electrocardiography was performed in the study mentioned above. The results of our larger group showed that the findings of those investigators were also valid for younger cases.

The increase in QTd is closely associated with repetitive and life-threatening ventricular arrhythmias and has been shown to be an independent risk factor for sudden death [8-14]. However, the factors which may act on QTd, such as age, gender, myocardial ischemia, cardiac failure, diabetes, hypertension and electrolyte imbalance and some drugs, and the circadian pattern of QTd, make its clinical use difficult [25]. By including age-, sex- and BMI-matched cases who were free of the disorders mentioned previously we tried to overcome these limitations.

The exact TSH value for which the treatment of SH should be started has not yet been clearly demonstrated $[6,7]$. Some investigators propose that cases whose TSH is over $10 \mathrm{mIU} / \mathrm{l}$ may benefit from L-thyroxine treatment, whereas cases with TSH between 5 and $10 \mathrm{mIU} / \mathrm{l}$ may have no additional benefit $[26,27]$. When compared to the control group, persistence of prolongation of QT interval and increase in QTd among our cases with the latter TSH levels seem to provide a new perspective to this argument. Accordingly, besides preventing the progression to overt hypothyroidism, early L-thyroxine treatment may be recommended for improving ventricular repolarization inhomogeneity among such cases.

Although there is no consensus on the reference limits of QTd, the average value is assumed to be between 10.5 and $71 \mathrm{~ms}$ in healthy populations $[28,29]$. Due to the limited number of subjects included, we were not able to detect the exact TSH value at which the QT interval began to disperse. Further population-based studies are needed.

Our study group had higher post-treatment TSH levels than the controls. There is no doubt that the results of electrocardiographic findings would have been statistically even stronger had the two groups had completely matched final TSH levels. However, as may be appreciated, it is not easy to predict the exact TSH level following L-thyroxine therapy.

\section{Conclusion}

We detected prolonged QT intervals and increased QTC among our SH cases. The prolongation remained significant for the whole group, as well as within the subgroups. There was a positive correlation between TSH levels and QTc. Return of serum TSH levels for $>10$ $\mathrm{mIU} / \mathrm{l}$ to values within the reference range resulted in normalization of QTc. Such an outcome for patients with TSH between 5 and $10 \mathrm{mIU} / \mathrm{l}$ remains to be investigated. 


\section{References}

-1 Tunbridge WM, Evered DC, Hall R, Appleton D, Brewis M, Clark F, Evans JG, Young E, Bird T, Smith PA: The spectrum of thyroid disease in a community: the Whickham survey. Clin Endocrinol (Oxf) 1977;7:481-493.

\2 Sawin CT, Castelli WP, Hershman JM, McNamara P, Bacharach P: The aging thyroid: thyroid deficiency in the Framingham Study. Arch Intern Med 1985;145:1386-1388.

$\checkmark 3$ Samuels MH: Subclinical thyroid disease in the elderly. Thyroid 1998;8:803-813.

$\checkmark 4$ Razvi S, Ingoe L, Keka G, Oates C, Mcmillan C, Weaver JU: The beneficial effect of L-thyroxine on cardiovascular risk factors, endothelial function and quality of life in subclinical hypothyroidism: randomised, crossover trial. J Clin Endocrinol Metab 2007;92:17151723.

5 Kahaly GJ: Cardiovascular and atherogenic aspects of subclinical hypothyroidism. Thyroid 2000;10:665-679.

-6 Ayala AR, Danese MD, Ladenson PW: When to treat mild hypothyroidism. Endocrinol Metab Clin North Am 2000;29:399-415.

$\checkmark 7$ Cooper DS: Clinical practice: subclinical hypothyroidism. N Engl J Med 2001;345:260265.

$\checkmark 8$ Day CP, McComb JM, Campbell RW: QT dispersion: an indication of arrhythmia risk in patients with long QT intervals. Br Heart J 1990;63:342-344.

D Hii JT, Wyse DG, Gillis AM, Duff HJ, Solylo MA, Mithell LB: Precordial QT interval dispersion as a marker of torsades de pointes: disparate effects of class Ia antiarrhythmic drugs and amiodarone. Circulation 1992;86: 1376-1382.

-10 Yunus A, Gillis AM, Duff HJ, Wyse DG, Mithell LB: Increased precordial QTc dispersion predicts ventricular fibrillation during acute myocardial infarction. Am J Cardiol 1996;78:706-708.
11 Zareba W, Moss AJ, Le Cessie S: Dispersion of ventricular repolarization and arrhythmic cardiac death in coronary artery disease. Am J Cardiol 1994;74:550-553.

12 Naas AA, Davidson NC, Thompson C, Cummings F, Ogston SA, Jung RT, Newton RW, Struthers AD: QT and QTc dispersion are accurate predictors of cardiac death in newly diagnosed non-insulin dependent diabetes: cohort study. BMJ 1998;316:745-746.

13 de Bruyne MC, Hoes AW, Kors JA, Hofman A, van Bemmel JH, Grobbee DE: QTc dispersion predicts cardiac mortality in the elderly: the Rotterdam Study. Circulation 1998;97: 467-472.

14 Okin PM, Devereux RB, Howard BV, Fabsitz RR, Lee ET, Welty TK: Assessment of QT interval and QT dispersion for prediction allcause and cardiovascular mortality in American Indians: the Strong Heart Study. Circulation 2000;101:61-66.

-15 Sarma JS, Venkataraman K, Nicod P, Polikar R, Smith J, Schoenbaum MP, Singh BN: Circadian rhythmicity of rate-normalized QT interval in hypothyroidism and its significance for development of class III antiarrhythmic agents. Am J Cardiol 1990;66:959963.

16 Fredlund BO, Olsson SB: Long QT interval and ventricular tachycardia of 'torsades pointes' type in hypothyroidism. Acta Med Scand 1983;213:231-235.

17 Altun A, Altun G, Özkan B, Kaya M, Özbay G: The relationship between ventricular repolarization and thyroid stimulating hor mone (abstract). Ann Noninvasive Electrocardiogr 1998;3:S19.

18 Galetta F, Franzoni F, Fallahi P, Rossi M, Carpi A, Rubello D, Antonelli A, Santoro G: Heart rate variability and QT dispersion in patients with subclinical hypothyroidism. Biomed Pharmacother 2006;60:425-430.

19 Malik M, Batchvarov VN: Measurement, Interpretation and clinical potential of QT dispersion. J Am Coll Cardiol 2000;36:17491766.
20 Bazett HC: An analysis of the time relations of the electrocardiograms. Heart 1920;7: 353-370.

$>21$ Surawicz B, Mangiardi ML: Electrocardiogram in endocrine and metabolic disorders. Cardiovasc Clin 1977;8:243-266.

$>22$ Binah O, Rubinstein I, Gilat E: Effects of thyroid hormone on the action potential and membrane currents of guinea pig ventricular myocytes. Pflugers Arch 1987;409:214-216.

$>23$ Rubinstein I, Binah O: Thyroid hormone modulates membrane currents in guinea-pig ventricular myocytes. Naunyn Schmiedebergs Arch Pharmacol 1989;340:705-711.

24 Bosch RF, Wang Z, Li GR, Nattel S: Electrophysiological mechanisms by which hypothyroidism delays repolarization in guinea pig hearts. Am J Physiol 1999;277:211-220.

25 Somberg JC, Molnar J: Usefulness of QT dispersion as an electrocardiographically derived index. Am J Cardiol 2002;89:291-294.

26 Chu JW, Crapo LM: The treatment of subclinical hypothyroidism is seldom necessary. J Clin Endocrinol Metab 2001;86:45914599.

-27 Vanderpump MP, Ahlquist JA, Franklyn JA, Clayton RN: Consensus statement for good practice and audit measures in the management of hypothyroidism and hyperthyroidism. The Research Unit of the Royal College of Physicians of London, the Endocrinology and Diabetes Committee of the Royal College of Physicians of London, and the Society for Endocrinology. BMJ 1996;313:539-544.

28 Shah CP, Thakur RK, Reisdorff EJ, Lane E, Aufderheide TP, Hayes OW: QT dispersion may be a useful adjunct for detection of myocardial infarction in the chest pain center. Am Heart J 1998;136:496-498.

-29 Davey PP, Bateman J, Mulligan IP, Forfar C, Barlow C, Hart G: QT interval dispersion in chronic heart failure and left ventricular hypertrophy: relation to autonomic nervous system and Holter tape abnormalities. $\mathrm{Br}$ Heart J 1994;71:268-273. 